\title{
Rule Based Decision Making For Innovative Post Disaster shelters
}

\author{
MahastiTafahomi \\ Shelterexpert.org (TheNetherlands)
}

\begin{abstract}
Representatives of the Boards of the Humanitarian Accountability Partnership (HAP), People In Aid and the Sphere Project [1] confirmed their continued commitment to improving quality and accountability within the humanitarian and development sectorsrecently. Recognition of the deep interest of joining forces and respective constituencies for developing joint standards however, did not lead to continuing the Joint Standards Initiative (JSI). The harmonization process of standards for post disaster aid and combining operational and organisational standards seems more difficult than originally assumed and might not be desirable. The Sphere Board has decided that the Sphere Project will discontinue its involvement in the development of a Core Humanitarian Standard and relatedactivities.Post-disaster emergency-sheltering requires that various relief agencies and other actors with different backgrounds cooperate in a tremendously short amount of time and under very different circumstances. Lives depend on the quality of aid and, specifically, on the quality of sheltering. Standards play an essential role in decision making process. Currently, the need for performance standards for optimal design and selection of post disaster emergency shelters is eminent. In this article, we describe the design process for an on-demand post disaster emergency shelter and demonstrate the need for performance standards, context sensitivity, crisis sensitivity in design and selection of innovative post disaster emergencyshelters.Performance standards are needed for developing decision tools for making rule based decisions in post disaster emergency shelter aid.
\end{abstract}

Keywords:Innovation, technology, post disaster shelters, performancestandards.

\section{Introduction}

The UNHCR encourages innovation in shelter design. The first step was the development of the family tentby the UNHCR, in conjunction with Lausanne Polytechnique (EPFL), and the ICRC, developed a new tent,. A cold climate version (winterized) and a version for tropical climates of this tent is being developed in cooperation with other technical humanitarian agencies. One of the innovative ideas is to print a solar circuit on the roof of the tents and, in the future, on the plastic sheeting for solar energy provision. Recent joint UNHCRIKEA foundation initiative is a new step for innovative shelters. The need for innovative post disaster shelters and the choice for providing high-tech or low-tech shelter designs are being discussed among relief organizations. The low-tech tent assembled from the rubble and local materials has been launched by the SRU at the Aidex 2013, the Sahel tent. However the high-tech innovative products are being presented at events as Aidex as well. A high-tech shelter introduces the modern world to a group of people who otherwise had no connection with the new developments. With the correct education a high-tech shelter can be a catalyst for improvement. However the usage of local materials and respect for the existing culture play a role in harmony andbalance.

The manufacturers still need to succeed to be presented in the catalogues of OXFAM or IFRC for example. The selection procedure depends on personal judgment of the staff, in occasions the administrative staff. The presentation of the innovative tents and the innovative products as the lamp the gravity at the Aidex show is an illustration for the arbitrary selection methods that currently are used for the selection of products.

Transparency and efficiency in decision making in design and selection of post disaster shelters can be optimized by implementation of a decision support system [11]. Finding the balance between the providing solutions for the basic needs and the improvement of living standards is vital for optimal shelter aid after a disaster. Figure 1 illustrates the interior of a shelter.

The heating source can be harmful for the children in the shelter. The shelter does have a floor made of local carpets. There is natural ventilation as a consequence of mal conjunction of the wall and the roof. There are no windows. The shelter is made of local wooden construction with plastics heeting. 


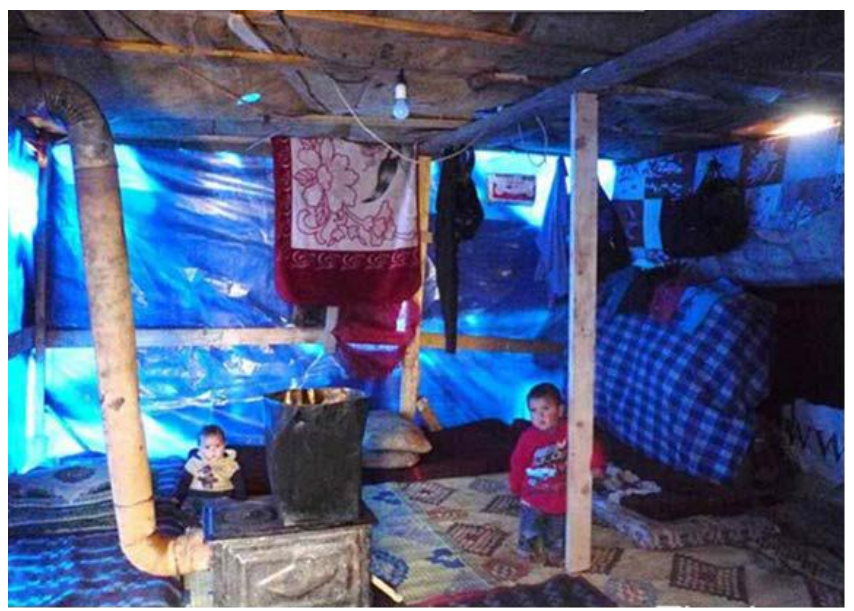

Fig. 1 Children in a refugee tent. photograph: 2013,save thechildren

\section{Meeting Thestandards}

Standards are the framework to function in the hectic environment of post-disaster emergency aid. The first initiative for standardization of the process of shelter aid, the sphere Project [1], was launched in 1997 by a group of humanitarian NGOs and the Red Cross and Red Crescent movement. They formulated a Humanitarian Charter and identified minimum standards to be attained in disaster assistance, in each of five sectors of aid: water supply and sanitation, nutrition, food aid, shelter and health services. This process led to the publication of the Sphere handbook in2000.

The Sphere Project was to develop a common framework and improve accountability for humanitarian aid. The Sphere Project is continuously being updated and developed. The updates and information is shared via the sphere handbook publications and via the website www.sphereproject.org. As a consequence, the humanitarian community mostly uses Sphere standards. In some cases, Sphere indicators and standards have been dismissed, as in the case of Pakistan where it was decided that "Sphere standards will not be met" (2005, IOM/JS - b/strategy-Internal working document ). According to the International Organization for Migration (IOM) working document, Shelter Cluster/Pakistan/ Post Earthquake Interim Emergency \& Transitional Shelter Strategy, for logistics reasons, as well as the need for consultations with the affected populations, it is not possible to provide fully adequate, standards compliant temporary housing to all affected populationsimmediately'.

Currently various guidelines for shelters are available. Each organisation has specific standards as the UNHCR handbook and the IFRC catalogue (Médecins Sans Frontières, 2002; Howard \& Spice, 1989; IAPSO, 2012; ICRC/IFRC, 2002; UNHCR, 2002; UNHCR, 2009). The Joint standards initiative was anattempttooptimizethespherestandardsincooperationwithotherrelieforganizations.

In the complex environment of post-disaster shelter relief, the task of creating optimal designs needs a systematic framework. The framework should take the following aspects intoaccount:

- context-sensitivity

- crisis-sensitivity

- $\quad$ 'performance standard'paradigm

Performance standards lead to a flexible design environment that leaves room for flexible, sustainable [4] shelter designs [2]. Local building standards play a role in shelter aid for a longer period oftime.

\section{Standards and System Flexibility}

In what manner can standards play a role in increasing the flexibility of the emergency sheltering system? The term flexibility refers to "the ease with which a system can adjust to changing circumstances and demands" [9]. In our case, it is the ability to provide the appropriate sheltering resources for any emergency situation. From the system theory perspective, there are two seemingly opposing views on the relation between standards and system flexibility: standards can be catalysts of entrenchment as well as instruments that facilitate change [10].

\subsection{On-Demand Sustainable Post-Disaster Emergencyshelters}

Designing a post disaster emergency shelter with the aid of a DSSneeds adaptive design thinking. The basic design is to be flexible. For this reason in cooperation with Industrialdesign.nl, we developed a basic design for a sustainable shelter that can be realized using the parameters of a decision support system (DSS) and can be adapted to each specific situation with the aid of the DSS. 
Acentralcolumninthesheltercanincludeadditionalpartsolutionsasenergy, waterandsanitation.

Figure 2 illustrates two possible shapes of the designed shelters. The frame and the central column provide a freedom for designs and flexibility to create culturally accepted shapes for the shelters. This means more acceptance and longer use of the shelters, thus more sustainable shelters. The frame can be replaced with self-supporting roof and wallelements.
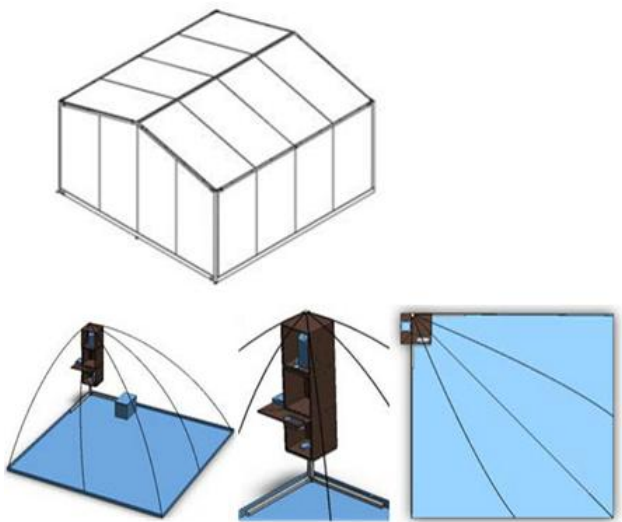

Fig. 2 The possiblesolutions

Shelter concept Industrialdesign.nl is an integral approach that includes the total functions of a shelter as a home. The packaging can be used as storage material in the shelter which reduces waste production. The shelter can provide an energy device and sanitation. This shelter has an additional module for training the beneficiaries for maintaining the parts if needed in the energy unite for example.

This design includes education in setting up small maintenance local businesses and local food production. The on-demand sustainable [4] post disaster emergency shelter is designed with the parameters as table oneshows.

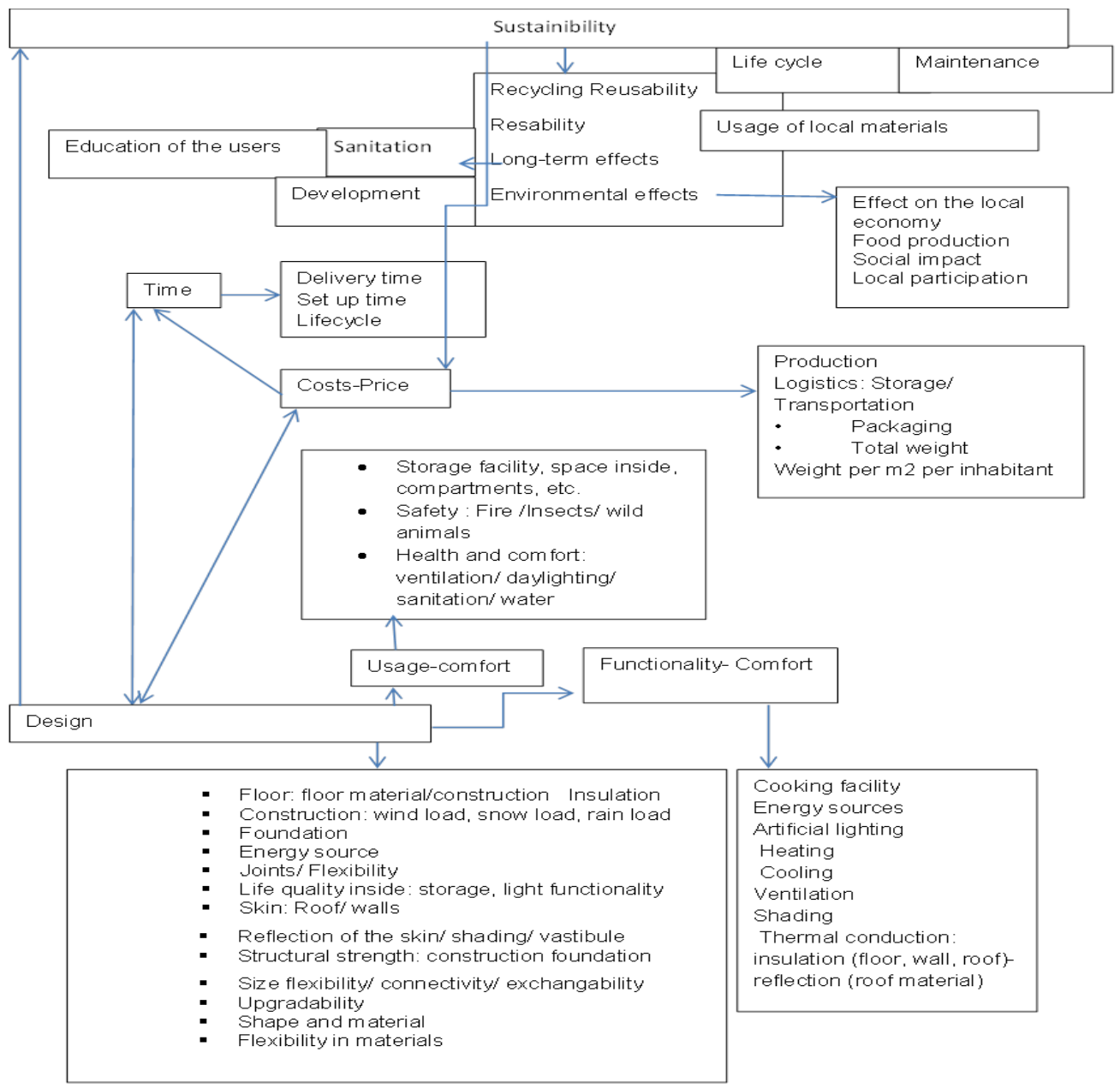


Table 1 The design and selection decisionproces

\section{Totalconcept}

The scheme of a post disaster emergency shelter can be summarizedas:

- Foundation

- Construction

- $\quad$ Floor: Insulation, Floorplane

- $\quad$ Shell: Roof, Façade, Walls,Insulation

- Joints

Lighting: Day-lighting, Artificiallighting

- $\quad$ Sanitation,

- $\quad$ Energy production: Heating, Cooling, Cooking,Lighting

- $\quad$ Energystorage

- Water: Drinking water, washing water, rainwater

- Ventilation

For each post disaster situation specific choices for foundation and other shelter parts can be made and the assembled solution will be packed in the centralcolumn.

Flexibility of the design is necessary for providing on-demand shelters after each disaster and in each situation. The proposed design contains a central column with variable content that, the construction and the skin- shell including the floor. Depending on the needs and the available solutions the content of the central column will be chosen. Sanitation, heating, cooking facilities can be included in the column. There are various options for the skin and the construction. As the central column provides flexible content, tailored solutions for each post-disaster situation can be offered. Figure 3 illustrates the position of the column in theshelter.

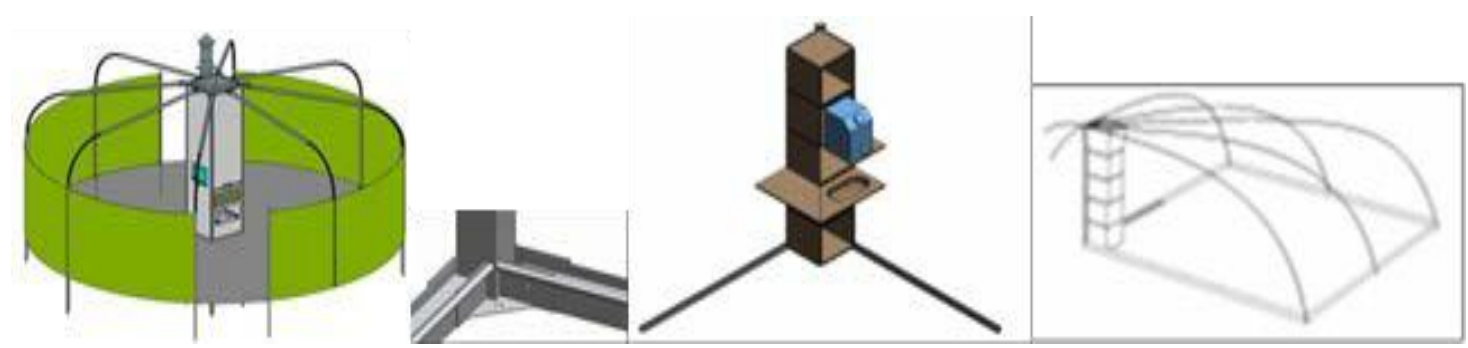

Fig. 3 The position of the column in the shelter construction, freedom ofshape

Based on the gathered evidence on needs and solutions the DSS can provide advice for tailored shelter solutions. The advice can be materialized with this shelter design approach. This approach will lead to more sustainable and tailored shelter solutions that meet the needs of the beneficiaries the most, as they are based on theneeds.

The design flexibility, needed for the provision of on-demand post disaster shelters, to meet the needs of each post disaster situation, the designers chose a concept with a frame, a shell and flexible joints, Figure 4.

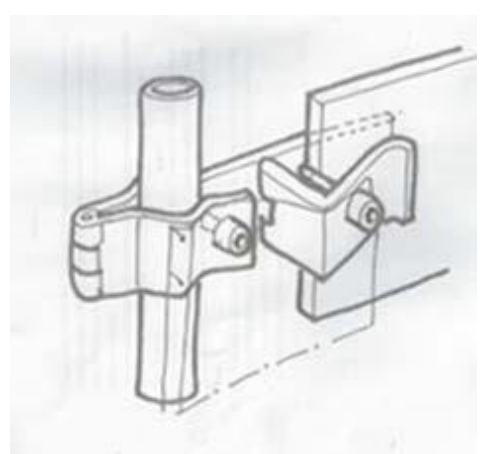

Fig. 4 The flexiblejoint

To meet the specific needs of the beneficiaries after each disaster, the DSS needs to provide advice for shelter parts and integral shelter designs. Water, sanitation and energy need to be included in the shelter advice. Figure 5 illustrates the design for the central water and sanitation unit, developed in this researchproject. 

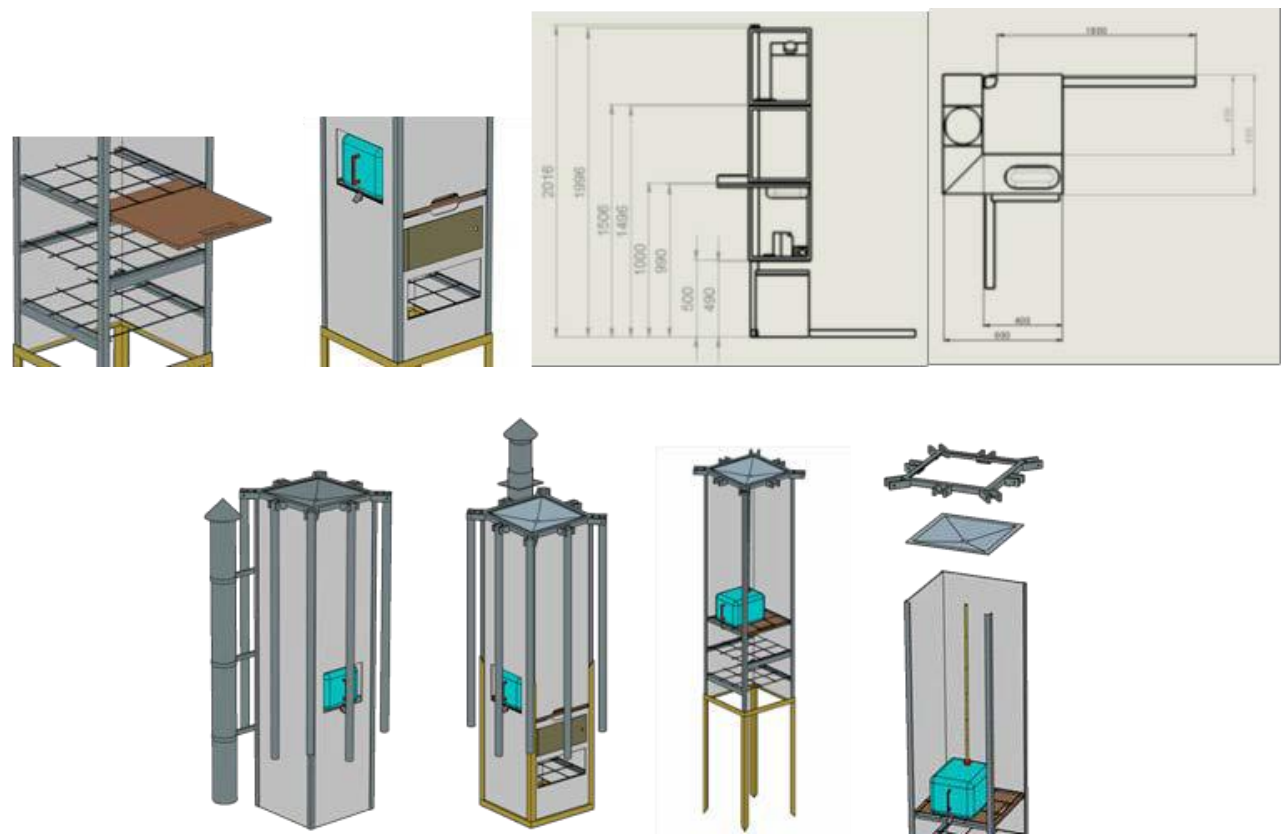

Fig. 5 the central column, can include energy, water and sanitation units (Johan Kok, Iindustrialdesign.nl).

An energy unite that can be adapted to the needs in each situation and meet the maintenance criteria is being investigated currently. Figure 6 illustrates the basic mobile energy unit that is developed and tested. The choice for wood, kerosene, solar panels or other sources, depend on the localconditions.

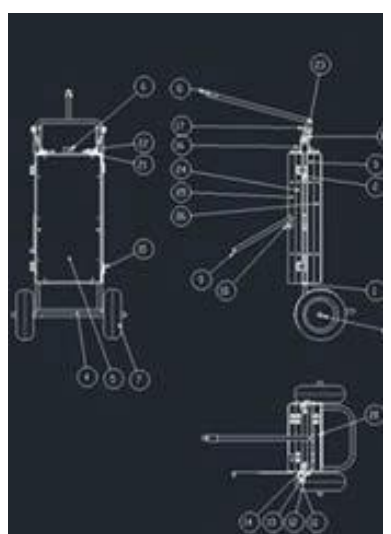

Fig. 6 The energy section can be delivered as a separate unite (Johan Kok,Iindustrialdesign.nl)

Regardingenergyprovision,theadviceprovidedbytheDSSistobebasedonlongtermeffectsoftheUsage of wood that results in deforestation, versus durable energy sources as solar energy or the fire sensitivity when using kerosene versus the usage of alternative energy sources that are currently less cost effective and need maintenance and technical know-how. The latter can mean educating the local population and growing localeconomy.

\section{Current Innovativeinitiatives}

The Cord aid ${ }^{1}$ timber housing initiative in Haiti, after the earthquake in 2010, is an illustration of post disaster shelters that can be used for long term reconstruction. An open source transitional shelter design realised by the local carpenters and in cooperation with the beneficiaries was donated[5].

1

A DutchNGO 
The need to transform emergency shelters to permanent homes resulted in development of transitional houses [7]. This need has resulted in the implementation of steel structures in a number of innovative post disaster shelterdesigns.

The following examples illustrate a number of innovative initiatives. We need to take into account that at the time of writing the UNHCR_ IKEA foundation initiative is the sole initiative that is being tested and codeveloped by a large humanitarian organization. Shelterexpert.org has supported industrialdesign.nl, and is a platform for guidance and displaying innovative designs. willing to test and guide all initiatives. As shelterexpert.org will not purchase any products, there are no constrains for advising commercial parties in development of innovative products. Shelterexpert.org needs a mandate from relief organizations to provide advice and test the products. This process is not limited totheshelters.Innovativeproductsasgravitylightcanbeincludedintheopenevaluationforproduct.

A IKEA shelter: IKEA foundation \&Refugee housing unit UNHCR. This concept has been guided by the UNHCR and has advantages regarding reflecting double roof and a hard insulated shell. A solar lamp is included. The packaging needs optimization and the cultural acceptance can cause a problem. The test criteria are not communicated with external parties (Figure7).
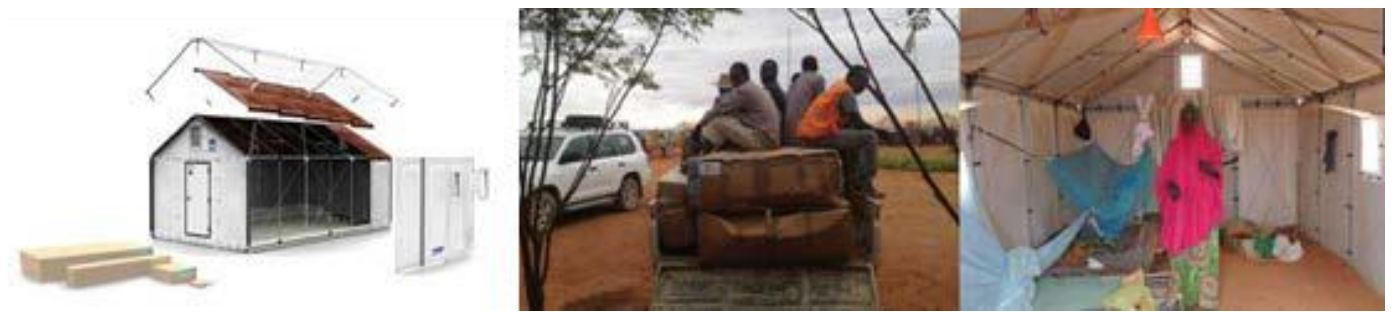

Fig 7 the Ikea-UNHCRconcept

B ROFI transitional tent: JahnAamodt design has an innovative frame construction, where the walls role in. The shelter can be upgraded. The focus is on the construction and skin materials Figure 8).

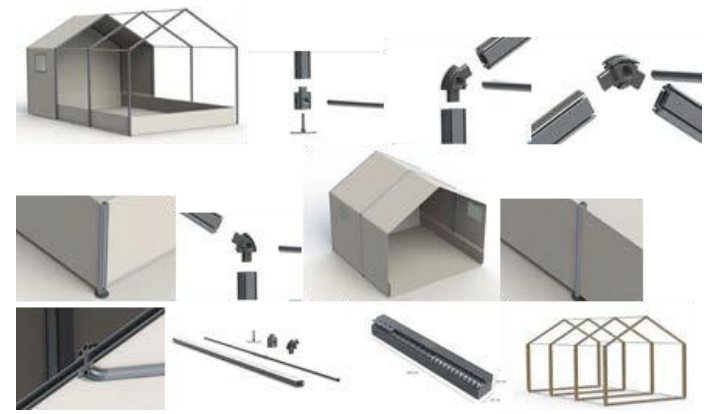

Fig. 8 The special profile ROFI C TT 200 Transitional tent: NRS international \&Losberger

Is an innovative shelter that is upgradeable and the focus has been on the construction and the skin. Figure 9 illustrates a prototypeconstruction.

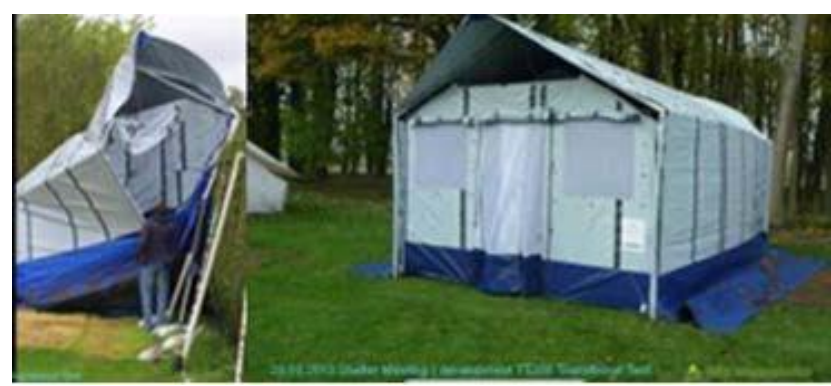

Fig 9 prototype TT200

D House built from accommodation cabins : UniversitadPolitecnica deMadrid

The costs of the containers may be higher than the other shelters ( $€ 7000$ versus the $€ 1000$ Ikea is calculating). However these containers offer different living standards and are suitable for certain cultural background. They 
may be easier reusable. Optimal testing is needed to compare these cases (Figure10).
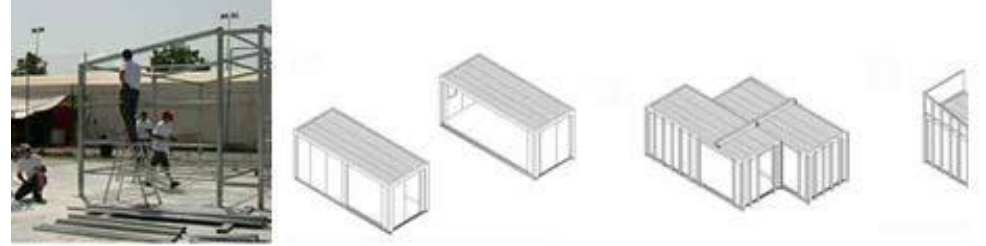

Fig.10

E Morethanshelters is a scientific project that involves various actors and has a broad approach. However the results to date are mostly focused on theconstruction.

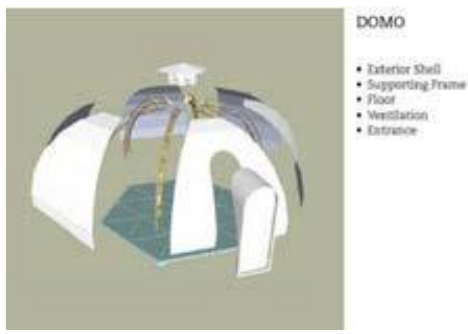

F Life shelter: Bestnet offers an innovative way for constructing a shelter. This shelter can be upgradedforpermanentusageandtransformedfromatenttosolidmaterials(Figure 11)

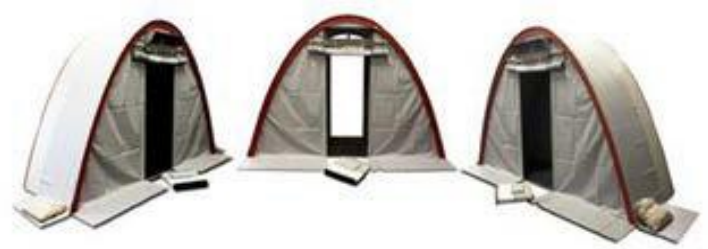

Fig.11 Lifeshelter

In addition to these prefabricated shelter solutions, the initiative eight designs [6] to design tailored habitats per location in cooperation with the users and considering the local parameters and the SRU approach that suggests gathering available materials from the area and combining them to a temporary shelter are initiatives that can be included in aDSS.

Objective tests with clear test criteria can provide the decision makers and the DSS with sufficient data for comparing and choosing the optimal shelter solution in each situation. The test can be conducted as:

1 Measurements in controlledenvironment

2 Field tests- users' tests to identify the usage andparameters.

\section{Conclusions And Recommendations}

The necessity of optimal and transparent decision making in post disaster shelter aid has been emphasized by various stake holders in the sector.

Performance standards for stimulating transparency and exchangeability in post disaster shelter aid, and therefore increasing the efficiency of the shelter relief has to be recognized by the international community. However standards are yet to be formulated in a way that stimulates innovation, flexibility, market transparency and improves the compatibility of various systems.

Recently discussions within the humanitarian community have been started about how to improve the delivery of quality and accountability of aid. The focus is on the use and relevance of current standards and the potential for a developing a compliance mechanism for verifying and benchmarking how well humanitarian agencies applyprinciples and standards of quality and accountability.

In this paper we demonstrated the steps that concern technical aspect of post disaster shelter aid.

An optimal decision for a shelter can be made within a flexible framework that is designed to serve as the basis for a (prototype) Decision Support System for emergency shelters. Performance standards are core instruments in achieving this. They deliver the flexibility which is crucial in the hectic environment of postdisaster emergency sheltering. 
Identifying the gaps in post- disaster shelter relief is the first step towards finding effective solutions. Analysis of the current post-disaster shelter relief has confirmed, as relief agencies have expressed earlier, that there is a major gap between the needs and the solutions in post-disaster emergency shelterrelief.For designing integral and on-demand design and engineering of sustainable post-disaster shelters can contribute to optimization of shelter aid by creating tailored solutions, more preparedness and less on site decision making.

The discussion on providing high-tech solutions after a disaster in less developed area's or using the locally known and available solutions for post disaster shelter aid, needs to be explored more in depth. Respecting the local traditions and usage of rubble and local materials is in many cases sustainable solutions. However providing innovative solutions in shelter, in combination with water and sanitation for example, can contribute to the improvement of the local community. Dependence on the technologies and educating local experts are to taken intoaccount.

Involvement and educating the beneficiaries are the key elements for a long-term sustainable post disaster shelter relief. The role of education becomes clearer when the disaster functions as a catalyst to introduce innovation to the affectedpopulation.

\section{References}

[1] The Sphereproject, (2003). The Sphere Handbook, HumanitarianCharterandMinimumStandards in HumanitarianResponse

[2] Tafahomi,M.Egyedi,T,DefiningFlexibleStandardsforPost-DisasterEmergencySheltering,Euras2008

[3] Alnap,(29March2012), areviewsessiononnewtechnologiesintheaidsector,jointlyhostedby ALNAP, CaLP ${ }^{2}$ and LMMS ${ }^{3}$, LondonU.K

[4] The BrundtlandReport, (1987), Our Common Future Oxford UniversityPress.

[5] Cordaid (2013). Haiti earthquake, 2010 - Shelter design with the community,shelterlibrary.

[6] Ashmore, J. etal . (2011). Transitional shelters- Eightdesigns, International Federation ofRedCross and Red CrescentSocieties.

[7] Corsellis, T. \& Vitale, A (2005). Transitional Settlement: Displaced Populations (TSDP). OXFAM

[8] Chalinder, A. (1998) UN report, Temporary Human Settlement Planning for DisplacedPopulations.

[9] Duncan NB. (1995) Capturing flexibility of information technology infrastructure: a study of resource characteristics and their measure. Journal of Management Information Systems 1995;

[10] Egyedi, T. (2001). 'Infrastructure flexibility created by standardized gateways

[11] Tafahomi, M (2016) Learning how to make optimal decisions in design and selection of post- disaster (IJERA)

2

Cash LearningPartnership

3

Last Mile MobileSolutions 